\title{
openheart Influence of case definition on incidence and outcome of acute coronary syndromes
}

\author{
Azam Torabi, ${ }^{1,2}$ John G F Cleland, ${ }^{3}$ Nasser Sherwi, ${ }^{1}$ Paul Atkin, ${ }^{1}$ Hossein Panahi, ${ }^{1}$ \\ Eric Kilpatrick, ${ }^{1}$ Simon Thackray, ${ }^{1}$ Angela Hoye, ${ }^{1}$ Farqad Alamgir, ${ }^{1}$ Kevin Goode, ${ }^{1}$ \\ Alan Rigby, ${ }^{1}$ Andrew L Clark $^{1}$
}

To cite: Torabi A, Cleland JGF, Sherwi N, et al. Influence of case definition on incidence and outcome of acute coronary syndromes. Open Heart 2016;3:e000487. doi:10.1136/openhrt-2016000487

Received 14 June 2016 Revised 29 September 2016 Accepted 18 October 2016

CrossMark

${ }^{1}$ Department of Cardiology, Castle Hill Hospital, Hull York Medical School, University of Hull, Kingston upon Hull, UK ${ }^{2}$ Department of

Cardiovascular and

Respiratory Studies, Castle

Hill Hospital, Kingston upon

Hull, UK

${ }^{3}$ National Heart \& Lung Institute, Imperial College, London, UK

Correspondence to Professor John Cleland; j.cleland@imperial.ac.uk

\section{ABSTRACT}

Objective: Acute coronary syndromes (ACS) are common, but their incidence and outcome might depend greatly on how data are collected. We compared case ascertainment rates for ACS and myocardial infarction (MI) in a single institution using several different strategies.

Methods: The Hull and East Yorkshire Hospitals serve a population of $\sim 560000$. Patients admitted with ACS to cardiology or general medical wards were identified prospectively by trained nurses during 2005. Patients with a death or discharge code of MI were also identified by the hospital information department and, independently, from Myocardial Infarction National Audit Project (MINAP) records. The hospital laboratory identified all patients with an elevated serum troponin$\mathrm{T}(\mathrm{TnT})$ by contemporary criteria $(>0.03 \mu \mathrm{g} / \mathrm{L}$ in 2005).

Results: The prospective survey identified 1731 admissions (1439 patients) with ACS, including 764 admissions (704 patients) with Mls. The hospital information department reported only 552 admissions (544 patients) with Ml and only 206 admissions (203 patients) were reported to the MINAP. Using all 3 strategies, 934 admissions (873 patients) for MI were identified, for which TnT was $>1 \mu \mathrm{g} / \mathrm{L}$ in $443,0.04$ $1.0 \mu \mathrm{g} / \mathrm{L}$ in $435, \leq 0.03 \mu \mathrm{g} / \mathrm{L}$ in 19 and not recorded in 37. A further 823 patients had $T n T>0.03 \mu \mathrm{g} / \mathrm{L}$, but did not have ACS ascertained by any survey method. Of the 873 patients with MI, 146 (16.7\%) died during admission and $218(25.0 \%)$ by 1 year, but ranging from $9 \%$ for patients enrolled in the MINAP to $27 \%$ for those identified by the hospital information department.

Conclusions: MINAP and hospital statistics grossly underestimated the incidence of $\mathrm{MI}$ managed by our hospital. The 1-year mortality was highly dependent on the method of ascertainment.

\section{BACKGROUND}

Although acute coronary syndromes (ACS), including myocardial infarction (MI), are common, there is a lack of robust epidemiological data about their incidence. ${ }^{1}$ Case ascertainment and selection bias could have a

\section{KEY QUESTIONS}

What is already known about this subject?

- Myocardial infarction (MI) is common, but the effect of the method of case ascertainment on its epidemiology has not been adequately explored.

- The prognosis of MI managed by cardiologists has improved markedly over the last 20 years but this could, at least in part, reflect the method of case ascertainment and selection.

- Plasma concentrations of troponins are often elevated in the absence of a clinically identified cardiac event.

What does this study add?

- This study shows that the incidence and outcome of $\mathrm{Ml}$ is highly dependent on the mode of ascertainment.

- It demonstrates that a raised troponin that is not associated with other features of an acute coronary syndrome (ACS) is associated with a particularly poor prognosis.

How might this impact on clinical practice?

- The observations will increase awareness of the uncertainty surrounding the incidence and outcome of ACS, the need for improved data collection and a review of resource requirements for the management of ACS.

- Further research may help improve diagnosis, management and outcomes for patients who do not have ACS, but have a raised troponin.

major impact on incidence and outcome statistics. This creates difficulty in planning appropriate resource allocation, doubt about the efficacy of coronary prevention at a population level and uncertainty about the overall effectiveness of management of ACS.

In late 1998, the UK launched the Myocardial Infarction National Audit Project (MINAP) and required all hospital trusts to report all MIs initially and subsequently a much broader range of patients. ${ }^{2}$ About 1 million 
cases of MI have been reported to the MINAP over the last 15 years. $^{3} \quad$ (https://www.ucl.ac.uk/nicor/audits/minap/ reports) These reports suggest that the quality of care for ACS in the UK is good or excellent. However, there are deep concerns about the completeness of, and case selection for, the MINAP returns that might misrepresent the true pattern of care.

We conducted a retrospective audit of all patients coded as having MI in our region in 1998. This identified 896 patients; of whom, 562 (63\%) subsequently developed heart failure and $480(54 \%)$ died during 6-year follow-up. ${ }^{4}$ We now report a new audit of MIs occurring in 2005 from the same region using the same and three additional methods for case ascertainment. This method gave us the opportunity of comparing the hospital incidence of MI using three different approaches and additionally making a historical comparison from the same region at a time of major changes in treatment and services.

\section{METHODS}

\section{Study population}

One hospital group in Hull and East Yorkshire provides all the acute cardiac services for $\sim 560000$ people; of whom, $\sim 300000$ are aged >35 years, living in a geographically distinct part of the UK. The Hull Infarction Project (HIP-2005) employed specialist cardiac nurses to try to identify all patients with ACS admitted during 2005 to the acute assessment or cardiac monitoring units and other medical wards. Case records were reviewed to verify the medical diagnosis, use of loop diuretics and serum concentrations of troponin $\mathrm{T}$ (TnT); results of imaging tests were obtained whenever available and treatment at discharge was recorded. The hospital information department provided all death and discharge data for acute MI and a record of all patients reported to the MINAP in 2005. We also received a report of all positive $(>0.03 \mu \mathrm{g} / \mathrm{L})$ TnT tests. Survival status was recorded until June 2014.

\section{HIP-2005 definitions}

Clinical criteria

ACS was defined as a diagnosis made by a cardiologist or, if the TnT was elevated, by a cardiac specialist nurse or a non-specialist doctor. ACS was subclassified as an MI or unstable angina by cardiologists. When the cardiologist did not specify, patients who had an elevated TnT or ST segment elevation on the ECG were considered to have had an MI and those who did not were reported as unstable angina. Patients with sudden death or cardiac arrest that was considered likely to be due to an ACS were included in the survey and considered to have had an MI if they had left bundle branch block (LBBB) or ST segment elevation or had a pre-existing increase in TnT.

Assessments of left ventricular function within 1 year after discharge were recorded. Criteria for left ventricular systolic dysfunction (LVSD) were left ventricular ejection fraction $<40 \%$ or a qualitative report of moderate or severe LVSD on echocardiography, first-pass radionuclide ventriculography or contrast angiography. Serum TnT was defined as positive if $>0.03 \mu \mathrm{g} / \mathrm{L}$ and strongly positive if $>1.0 \mu \mathrm{g} / \mathrm{L}$. High-sensitivity TnT was not introduced until after December 2010.

\section{MINAP criteria}

The MINAP seeks to enrol all patients with symptoms suggestive of an ACS admitted to the hospital in England and Wales (population $\sim 50$ million), ${ }^{5}$ although we suspect, in practice, that many hospitals report only patients who have been considered for thrombolysis or coronary intervention. From January 2004 until March 2005, 88782 patients were reported to have had an MI by the MINAP. ${ }^{6}$ The discharge diagnosis of ACS is made by the medical staff caring for the patient in the light of standard investigations, including clinical history, ECG and troponin. Patients' data were entered by the clinical audit staff into a central database. ${ }^{57}$

\section{Hospital coding system}

The hospital employs specialised coding staff who review and code the case notes of all deaths and discharges regardless of cause, including data from postmortem examinations, using ICD- $10 .{ }^{8}$ The codes are used to generate central returns to the NHS and for reimbursement. Acute MI was coded as I21, subsequent MI as I22, silent MI as I25.6 and complications following acute MI as I23.

\section{Laboratory-positive TnT}

Serum TnT (Roche Diagnostics) was measured in a single laboratory for the whole region. Values $>0.03 \mu \mathrm{g} /$ $\mathrm{L}$ were considered positive. We collected all positive troponins, and the hospital information department provided us with the discharge diagnosis of patients who had a positive TnT, but were not diagnosed as ACS by any of the other three methods.

\section{Statistical analysis}

Data were analysed using SPSS (V.16.0). Categorical data are presented as percentages and continuously distributed data as median and IQR. Estimating the probability of death at day 30, 1 and 3 years was calculated by using moving average estimator curves in patients who had TnT report after dividing them into patients with and without a diagnosis of ACS.

Survival curves are plotted by the Kaplan-Meier method and compared by the log-rank test. An arbitrary level of $5 \%$ statistical significance (two-tailed) is assumed.

\section{RESULTS}

\section{Overall results}

Of 1764 admissions identified with ACS by HIP-2005, 33 were excluded from further analysis because they had 


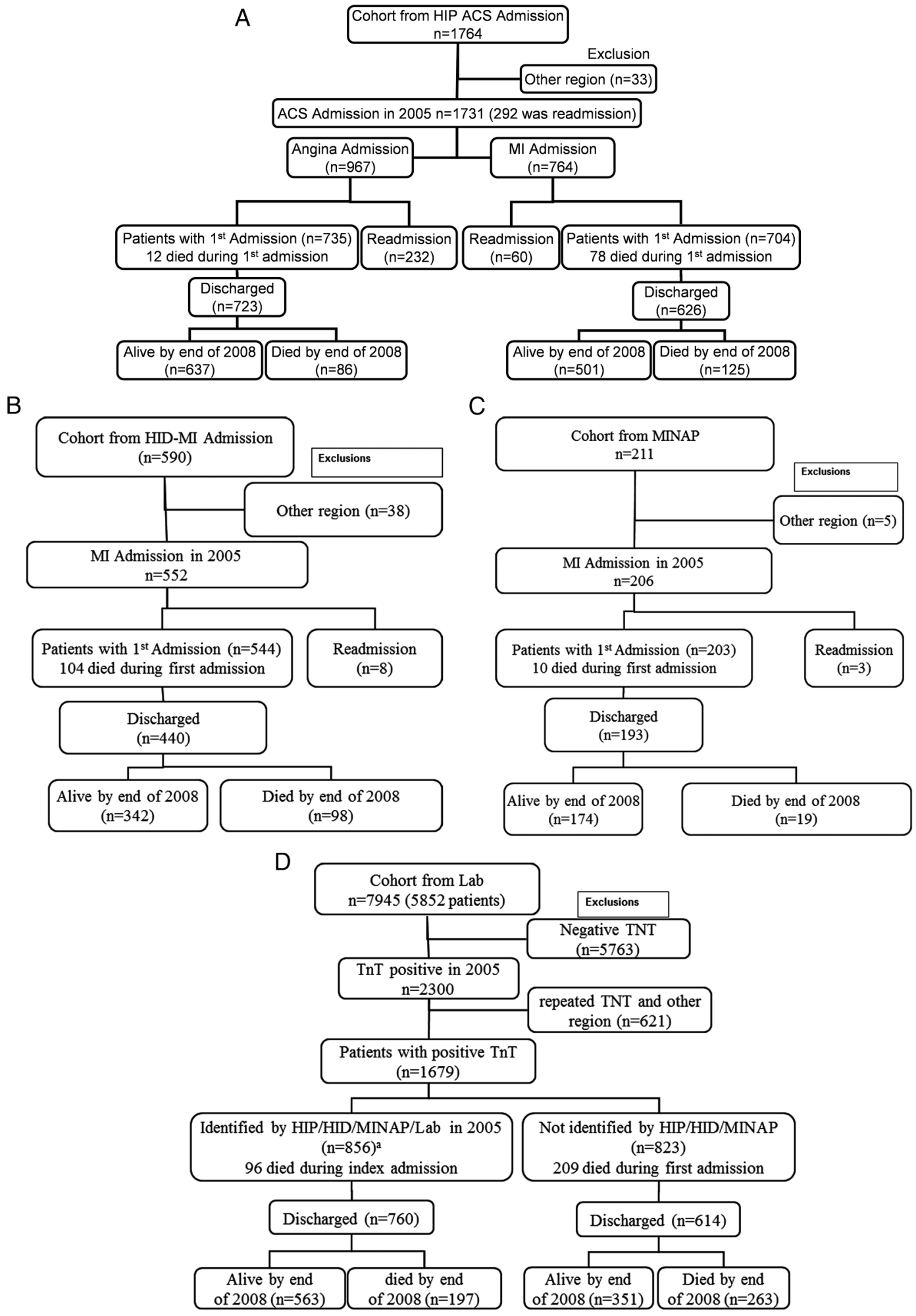

Lab; laboratory. a36 of them identified by HIP as ACS but negative TnT during 1st admission.

Figure 1 (A) Incidence of ACS and MI identified by the HIP. (B) Incidence of MI identified by the hospital information department (HID). (C) Incidence of MI identified by the MINAP. (D) Laboratory report of TnT during 2005 and sequence of mortality until the end of 2008. ACS, acute coronary syndromes; HIP, Hull Infarction Project; MI, myocardial infarction; MINAP, Myocardial Infarction National Audit Project; TnT, troponin T. 
been transferred from another region. This left 1439 unique patients with 1731 admissions for the main analysis; of which, 292 were readmissions within the same year, including 148 with one readmission and 55 with multiple readmissions. Of the 1731 admissions identified in HIP-2005, 764 (704 patients and 60 readmissions) were classified as MI and 967 (735 patients and 232 readmissions) as angina (figure 1A). During the index hospitalisation, only about half were managed, at least in part, by a consultant cardiologist and only 199 (14\%) patients had percutaneous transluminal coronary angioplasty.

Using the hospital information department, only 552 admissions with MI (544 patients and 8 readmissions) were identified. Using the MINAP, only 206 admissions (203 patients and 3 readmissions) for MI were identified (figure 1B, C).

Of the 764 admissions (704 patients) identified by HIP-2005 with MI, 388 (381 patients) were also identified by hospital discharge codes and 186 (183 patients) by the MINAP. Hospital discharge codes identified an additional 164 admissions (163 patients) with MI not identified by HIP-2005; of whom, 140 patients had an elevated TnT, including 80 who had values $>1.0 \mu \mathrm{g} / \mathrm{L}$. In addition, five patients were identified as having MI by the MINAP but not by other methods; two of these were identified as angina by HIP-2005, three had a negative troponin and two had no record of troponin being measured. Overall, the three methods of surveillance identified 933 admissions (872 patients) with MI and 1896 admissions (1603 patients) with ACS (figures 2 and 3A, B).
The laboratory reported $7945 \mathrm{TnT}$ tests (2300 with positive TnT) in 5852 patients during 2005. After excluding patients from regions other than those in the hospitals primary catchment area, of the 1679 patients with a positive TnT, 823 patients were not reported as having ACS by any of the other three routes of ascertainment. Eighty-five $(10 \%)$ of these had values of TnT $>1 \mu \mathrm{g} / \mathrm{L}$. These patients were older than those in the other groups (figure 1D and table 1).

For patients enrolled through the HIP-2005 survey, ST segment elevation MI (STEMI) was present in 328 (23\%) patients on their first admission, and an additional nine patients had STEMI during readmission. Seventy-one (5\%) patients had LBBB; of whom, 43 were diagnosed as having angina and 28 were managed as having MI. Thrombolysis was given to 227 of 356 (64\%) patients during their first admission and an additional four patients on readmission. The 'door-to-needle' time was available for 228 admissions and the median time was $30 \mathrm{~min}$ (IQR 20-63). This compares to 203 patients with STEMI or MI with LBBB identified by the Hull MINAP (of whom, 3 had a further readmission with STEMI); of whom, 197 received thrombolysis with a door-to-needle time of 30 (IQR 20-51) min. Similar data were not available for patients identified by the hospital information department or laboratory TnT.

Table 2 summarises the ICD-10 discharge codes for the 823 patients with positive TnT but not reported as ACS. For the three commonest diagnosis, namely heart failure, infections and chest pain, the median ages were 77 (70-83), 81 (74-88) and 75 (64-82) years; of which,
Figure 2 Incidence of $\mathrm{Ml}$ in all three data sets HIP, HID and MINAP. HIP, Hull Infarction Project; MI, myocardial infarction; MINAP, Myocardial Infarction National Audit Project.

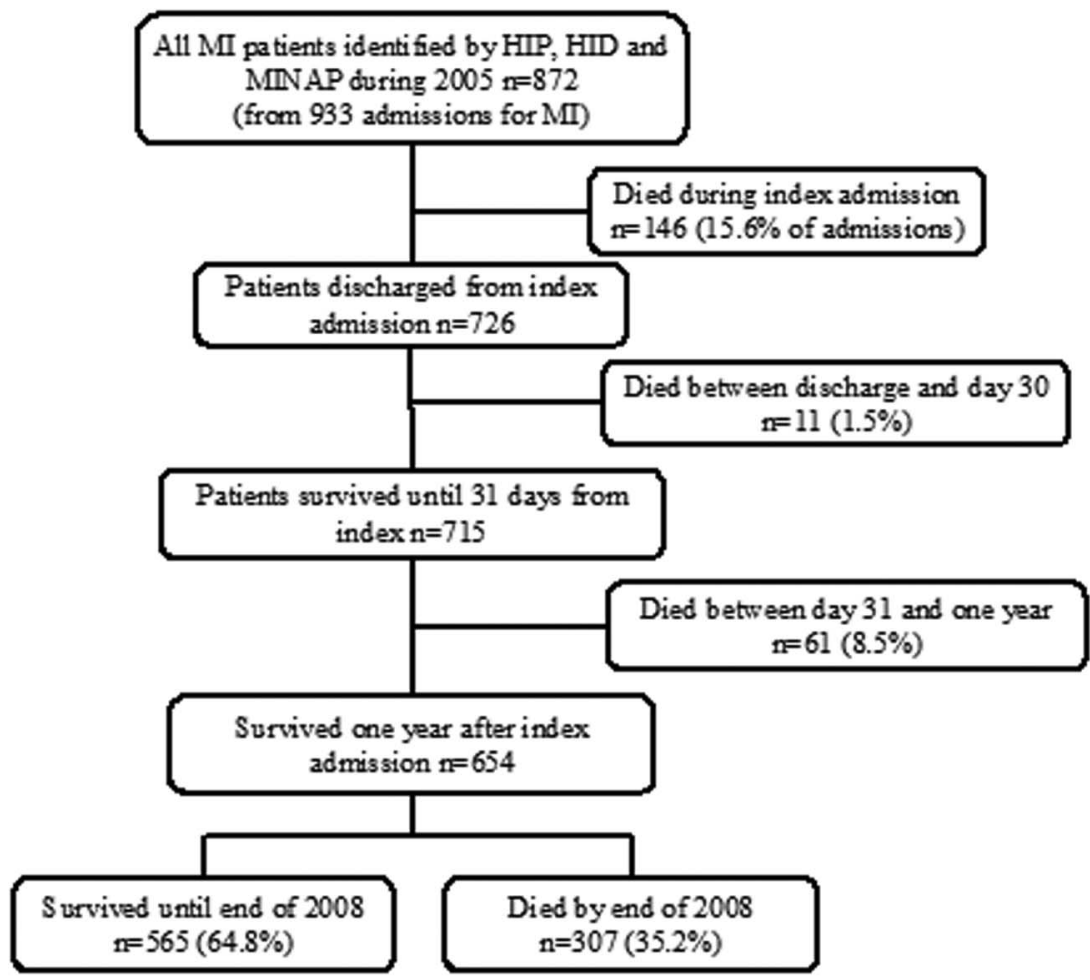


Figure 3 (A) Patients with MI identified by HIP, HID and MINAP with highest TnT in 2005. (B) Patients with ACS identified by HIP, HID and MINAP with highest TnT in 2005. ACS, acute coronary syndromes; HIP, Hull Infarction Project; MI, myocardial infarction; MINAP, Myocardial Infarction National Audit Project; $\mathrm{TnT}$, troponin $\mathrm{T}$.
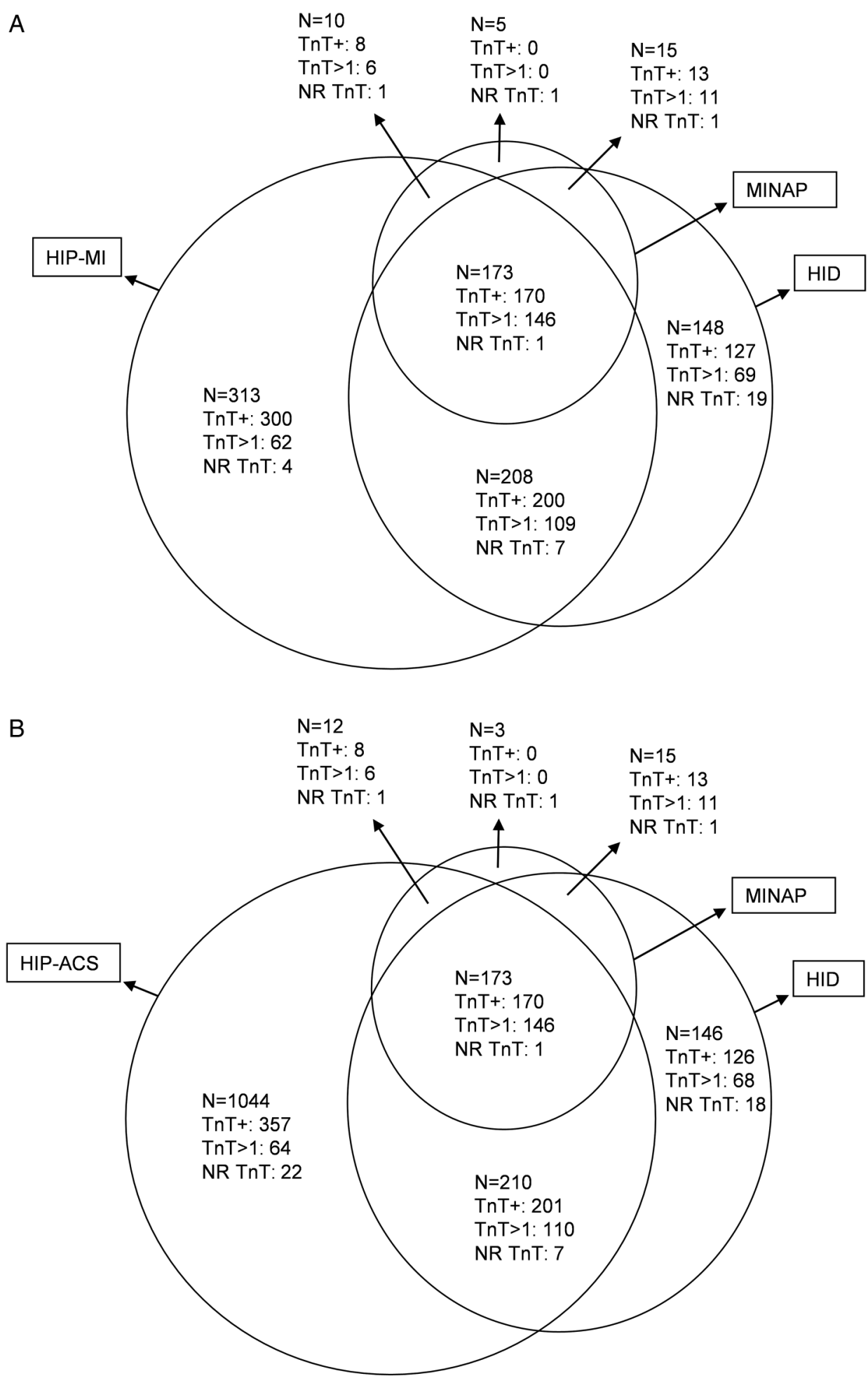

$56(41 \%), 64(50 \%)$ and $42(41 \%)$ were women, respectively.

\section{Mortality according to TnT during first admission in all patients identified by HIP-2005, HID, MINAP and laboratory-positive TnT}

Overall, 2426 individual patients were identified by HIP-2005, HID, MINAP or a positive TnT as potentially having an ACS. Among these, serum TnT was $\leq 0.03 \mu \mathrm{g} / \mathrm{L}$ in $708,>0.03-1.0 \mu \mathrm{g} / \mathrm{L}$ in $1188,>1.0 \mu \mathrm{g} / \mathrm{L}$ in 474 and was the test not performed in 56 patients (figure 4 and table 3 ).

Of the 1662 patients with elevated TnT, only 839 $(50 \%)$ were diagnosed with ACS by one of the survey methods. Of the 1547 patients with ACS by at least one survey method, $708(46 \%)$ had a negative TnT. Patients with values of $\mathrm{TnT}>0.03 \mu \mathrm{g} / \mathrm{L}$ had a higher mortality rate, but mortality was similar regardless of 
Table 1 Patient characteristics recorded during the index admission (data are median (IQR) and number occurring (\%))

\begin{tabular}{|c|c|c|c|c|c|c|}
\hline Variables & ACS-HIP & MI-HIP & MI-HInfoD & MI-MINAP & TnT +ve only & $\begin{array}{l}\text { Any case } \\
(\mathrm{ACS}, \mathrm{MI} \text { or } \mathrm{TnT}+\mathrm{ve})\end{array}$ \\
\hline $\mathrm{N}$ & 1439 & 704 & 544 & 203 & 823 & 2426 \\
\hline Age (years) & $67(58-77)$ & $69(59-78)$ & $71(60-80)$ & $65(56-73)$ & 77 (69-84) & $72(61-81)$ \\
\hline Age $>75$-men & $181(21 \%)$ & $113(24 \%)$ & $95(27 \%)$ & $18(13 \%)$ & $211(47 \%)$ & $440(32 \%)$ \\
\hline Age $>75$-women & 224 (38\%) & $117(49 \%)$ & $102(54 \%)$ & $18(29 \%)$ & $250(67 \%)$ & $511(50 \%)$ \\
\hline Women & $591(41 \%)$ & 241 (34\%) & $189(35 \%)$ & $63(31 \%)$ & $375(46 \%)$ & $1029(42 \%)$ \\
\hline $\mathrm{TnT} \geq 0.03^{*} \mu \mathrm{g} / \mathrm{L}$ & $724(50 \%)[34]$ & $678(98 \%)$ [13] & $510(99 \%)[27]$ & $191(96 \%)[4]$ & 823 & $1698(71 \%)[51]$ \\
\hline $\mathrm{TnT}>1.0^{*} \mu \mathrm{g} / \mathrm{L}$ & $324(23 \%)[34]$ & $323(47 \%)$ [13] & $335(65 \%)[27]$ & $163(82 \%)[4]$ & $85(10 \%)$ & $491(21 \%)[51]$ \\
\hline History of diabetes & $227(16 \%)$ & $104(15 \%)$ & $\mathrm{n}$ & $n$ & $166(20 \%)$ & $\mathrm{n}$ \\
\hline History of MI & 246 (17\%) & $103(15 \%)$ & $\mathrm{n}$ & $\mathrm{n}$ & $\mathrm{n}$ & $\mathrm{n}$ \\
\hline History of hypertension & $541(38 \%)$ & $255(36 \%)$ & $n$ & $n$ & $\mathrm{n}$ & $n$ \\
\hline Loop diuretic $\mu \mathrm{g} / \mathrm{L}$ & 305 (21\%) & $162(23 \%)$ & $\mathrm{n}$ & $15(12 \%)[81]$ & $\mathrm{n}$ & $\mathrm{n}$ \\
\hline Aspirin & $1027(71 \%)[2]$ & $517(74 \%)[2]$ & $n$ & $144(97 \%)[55]$ & $\mathrm{n}$ & $n$ \\
\hline ACE inhibitor & $589(41 \%)[1]$ & $374(53 \%)[1]$ & $\mathrm{n}$ & $121(92 \%)[71]$ & $\mathrm{n}$ & $\mathrm{n}$ \\
\hline Angiotension receptor blocker & $82(6 \%)[1]$ & $30(4 \%)[1]$ & $n$ & $2(3 \%)[127]$ & $\mathrm{n}$ & $n$ \\
\hline$\beta$ blocker & $873(61 \%)[1]$ & $473(67 \%)[1]$ & $\mathrm{n}$ & $120(91 \%)$ [71] & $\mathrm{n}$ & $\mathrm{n}$ \\
\hline Aldosterone antagonist & $59(4 \%)[1]$ & $37(5 \%)[1]$ & $\mathrm{n}$ & $5(4 \%)[82]$ & $\mathrm{n}$ & $n$ \\
\hline Statin & $979(68 \%)$ & $513(73 \%)$ & $\mathrm{n}$ & $132(95 \%)[64]$ & $\mathrm{n}$ & $\mathrm{n}$ \\
\hline Report on LV function available & $703[736]$ & 409 [295] & 293 [251] & $125[78]$ & 298 [525] & $1055[1371]$ \\
\hline LVSD & 236 (34\%) & $173(42 \%)$ & $142(48 \%)$ & $47(38 \%)$ & $134(45 \%)$ & 401 (38\%) \\
\hline Sodium & $139(137-141)[18]$ & $139(137-140)[2]$ & $139(136-140)[3]$ & $138(136-140)[1]$ & $138(136-141)[8]$ & $139(137-141)[27]$ \\
\hline $\mathrm{K}$ & $4.3(4-4.5)[71]$ & $4.3(4-4.6)[23]$ & $4.3(4-4.6)[24]$ & $4.2(4-4.5)[8]$ & $4.3(3.9-4.7)[43]$ & $4.3(4.0-4.6)[122]$ \\
\hline eGFR† & $69(53-83)[18]$ & $64(49-79)[2]$ & $64(44-77)[3]$ & $69(54-85)[1]$ & $48(31-68)[11]$ & $62(43-78)[33]$ \\
\hline eGFR <60‡ & $473(33 \%)$ & $279(40 \%)$ & $230(43 \%)[3]$ & $66(33 \%)$ & $539(66 \%)$ & $1109(46 \%)$ \\
\hline eGFR $<30$ & $94(6.5 \%)$ & $67(9.5 \%)$ & $66(12.1 \%)$ & $9(4.4 \%)$ & $191(23 \%)$ & $321(13 \%)$ \\
\hline WCC & $8.6(6.9-10.9)[28]$ & $9.9(7.8-12.2)[10]$ & $10.7(8.35-13.6)[13]$ & $10.6(8.5-13.1)[2]$ & $10.7(8.1-14.5)[21]$ & $9.3(7.2-9.3)[55]$ \\
\hline Diabetic & 252 (17.5\%) & $119(16.9 \%)$ & $83(15.3 \%)$ & $24(11.8 \%)$ & $166(20 \%)$ & $443(18 \%)$ \\
\hline Anaemia in first available $\mathrm{Hb} \S$ & $333(24 \%)[27]$ & $193(28 \%)[10]$ & $165(31 \%)[13]$ & 37 (18\%) [2] & $451(56 \%)[21]$ & $861(36 \%)[57]$ \\
\hline In-patient mortality & $87(6 \%)$ & $78(11 \%)$ & $104(19 \%)$ & $10(5 \%)$ & $209(25 \%)$ & $342(14 \%)$ \\
\hline 30-day Mortality & $96(7 \%)$ & $84(12 \%)$ & $101(19 \%)$ & $12(6 \%)$ & $187(23 \%)$ & $343(14 \%)$ \\
\hline One-year mortality & $179(12 \%)$ & $134(19 \%)$ & $149(27 \%)$ & $19(9 \%)$ & $334(41 \%)$ & $597(25 \%)$ \\
\hline Overall mortality by end of 2008 & $301(21 \%)$ & $203(29 \%)$ & $202(37 \%)$ & $29(14 \%)$ & $472(57 \%)$ & 877 (36\%) \\
\hline Overall mortality by June 2014 & $542(38 \%)$ & $326(46 \%)$ & $283(52 \%)$ & $55(27 \%)$ & $600(73 \%)$ & $1269(52 \%)$ \\
\hline
\end{tabular}

Overall mortality by June 2014

$542(38 \%)$

$326(46 \%)$

Any case means a patient who belonged to any one of the other groups.

*Double-counting is possible because some patients had multiple admissions with a positive troponin, only some of which were identified as admissions with ACS

†Four-variable formula derived from the modification of diet in renal disease study (4V MDRD), GFR=186×(Creat/88.4) $-1.154 \times A g e-0.203 \times 0.742$ if female $\times 1.212$ if African Caribbean, was used to estimate the GFR.

teGFR $<60$ was defined as eGFR $<60 \mathrm{~mL} / \mathrm{min} / 1.73 \mathrm{~m}^{2}$.

$\S$ Anaemia: WHO criteria for anaemia are used (man $<13 \mathrm{~g} / \mathrm{dL}$ and woman $<12 \mathrm{~g} / \mathrm{dL}$ ).

ACS, acute coronary syndrome; any case, all ACS-HIP (MI and unstable angina in HIP), MI-HID, MI-MINAP and TnT +ve; eGFR, estimated glomerular filtration rate; GFR, glomerular filtration rate; HInfoD, Hospital Information Department; HIP, Hull Infarction Project; LVSD, left ventricular systolic dysfunction; MI, myocardial infarction; MINAP, Myocardial Infarction National Audit Project; TnT +ve, positive troponin T; WCC, white cell count. 
Table 2 Discharge diagnosis in patients with elevated $\mathrm{TnT}$ who were not diagnosed as ACS by any of the three methods of ascertainment $(\mathrm{N}=823)$

\begin{tabular}{lcc}
\hline & $\begin{array}{c}\text { First } \\
\text { diagnosis }\end{array}$ & $\begin{array}{c}\text { Second } \\
\text { diagnosis }\end{array}$ \\
\hline Chest pain & 103 & 13 \\
Heart failure & 137 & 27 \\
Stroke & 28 & 5 \\
Seizure & 4 & 0 \\
Cardiac arrest & 10 & 3 \\
Ventricular tachycardia & 16 & 2 \\
Supraventricular tachycardia & 41 & 41 \\
Pulmonary thromboembolism & 15 & 3 \\
Other cardiovascular & 43 & 4 \\
Ischaemic heart disease & 44 & 18 \\
Renal disease & 17 & 46 \\
Cancer & 51 & 11 \\
Septicaemia & 21 & 7 \\
Infection & 129 & 37 \\
Chronic obstructive pulmonary & 61 & 5 \\
disease & & \\
Trauma or fracture & 35 & 0 \\
Haemorrhage & 2 & 2 \\
Other & 49 & 2 \\
Not reported & 17 & 0 \\
\hline ACS, acute coronary syndrome; TnT, troponin T. &
\end{tabular}

concentration above this (figure 5A). Patients with a positive TnT who were not identified as having ACS (figure 5B) by one of the survey methods had a worse prognosis $(41 \%)$ at 1 year than those with ACS (figure 5C), whether the patients with ACS were TnT-positive (mortality 23\%; $\mathrm{p}=0.0001$ ) or not (mortality 6\%; $\mathrm{p}=0.0001)$. Patients with ACS also had worse mortality at 30 days and at 3 years (figure 5B). Survival was poorest in patients with a positive TnT test and no ACS $(\mathrm{p}<0.001)$ compared to the other two groups (figure 6$)$.

\section{Loop diuretic and survival after discharge}

Information on diuretic treatment was available in 1439 patients with ACS from the HIP-2005 population. Of the 703 patients with $\mathrm{TnT} \leq 0.03 \mu \mathrm{g} / \mathrm{L}, 698$ survived the index admission and $126(18 \%)$ were discharged on loop diuretic, and 572 were not discharged on a loop diuretic; of whom, $34(27 \%)$ and $42(7 \%)$, respectively, had died by the end of 2008. Of the 700 patients with TnT $>0.03 \mu \mathrm{g} / \mathrm{L}$ included in HIP-2005, 633 survived the index admission and $144(23 \%)$ were and $489(77 \%)$ were not discharged on a loop diuretic; of whom, 67 $(47 \%)$ and $69(14 \%)$ had died by the end of 2008 (figure 7).

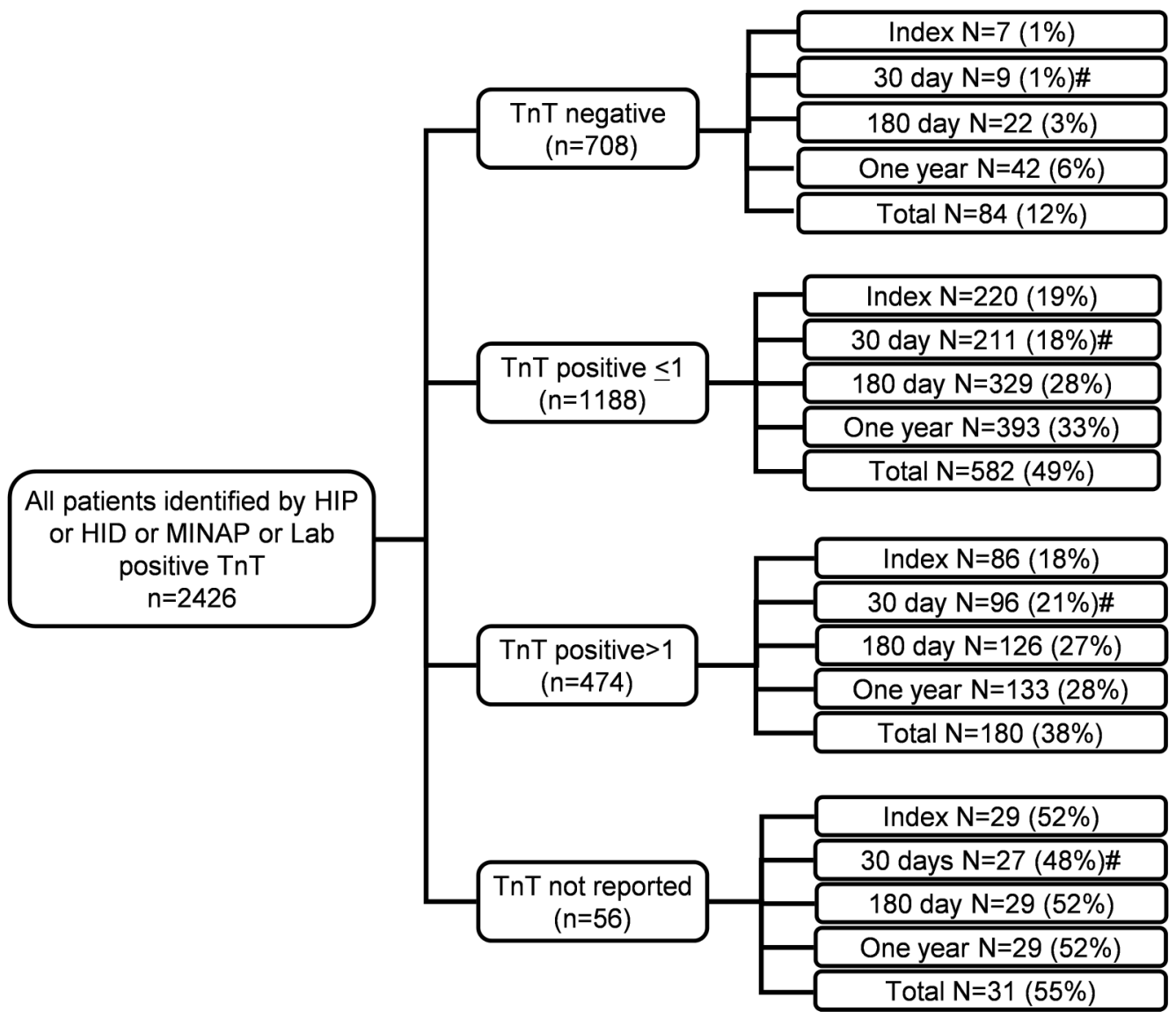

Figure 4 Mortality by the end of 2008 from first admission in all patients with ACS identified by HIP, HID, MINAP and positive TnT in 2005. ACS, acute coronary syndromes; HIP, Hull Infarction Project; MINAP, Myocardial Infarction National Audit Project; $\mathrm{TnT}$, troponin $\mathrm{T}$. 
Table 3 Mortality during index admission, 1 year, by end of 2008 and June 2014 according to serum TnT concentration

\begin{tabular}{lrrrrr}
\hline & All & $\begin{array}{l}\text { In-patient } \\
\text { mortality }\end{array}$ & $\begin{array}{l}\text { One-year } \\
\text { mortality }\end{array}$ & $\begin{array}{l}\text { Overall mortality } \\
\text { by end of 2008 }\end{array}$ & $\begin{array}{l}\text { Overall mortality } \\
\text { by June 2014 }\end{array}$ \\
\hline $\mathrm{TnT} \leq 0.03 \mu \mathrm{g} / \mathrm{L}$ & 708 & $7(1 \%)$ & $42(6 \%)$ & $84(12 \%)$ & $202(29 \%)$ \\
$\mathrm{TnT} 0.03-1 \mu \mathrm{g} / \mathrm{L}$ & 1188 & $220(19 \%)$ & $393(49 \%)$ & $582(49 \%)$ & $787(66 \%)$ \\
$\mathrm{TnT}>1 \mu \mathrm{g} / \mathrm{L}$ & 474 & $86(18 \%)$ & $133(28 \%)$ & $180(38 \%)$ & $242(51 \%)$ \\
$\mathrm{TnT}$ not reported & 56 & $29(52 \%)$ & $29(52 \%)$ & $31(55 \%)$ & $38(68 \%)$ \\
\hline TnT, troponin T. & & & &
\end{tabular}

\section{Left ventricular function}

Of the 1352 patients with ACS identified by HIP-2005 who survived the index admission, no record of an assessment of LV function could be identified for 685 (51\%) patients from their case notes or hospital systems during the subsequent year. Of the 667 patients who had LV function assessed, 206 patients (30\%) had LVSD. Mortality by the end of 2008 was $31 \%$ in those with LVSD, $12 \%$ in those without LVSD and $14 \%$ for those with no report of LV function.

\section{DISCUSSION}

The present report demonstrates that the incidence of ACS is highly dependent on the method of ascertainment, with a 10-fold difference depending on the criteria applied. An audit may appear excellent when applied to a subset of carefully selected patients; but when applied to all those requiring care, it may appear poor. We found that no single survey method identified $>60 \%$ of the 2426 patients who might have had ACS. The incidence of MI also varied threefold depending on the method of ascertainment. Herrett et at also indicated that fewer than $50 \%$ of MIs reported in electronic records, such as Hospital Episode Statistics (HES) or Clinical Practice Research Database (CPRD), were reported to the MINAP. Our data extend this observation to other methods that can be used to identify patients with ACS. The high mortality among patients with a raised TnT on a 'first-generation' assay but who were not identified by any other survey method is also cause for concern. Clearly, surveys that focus on
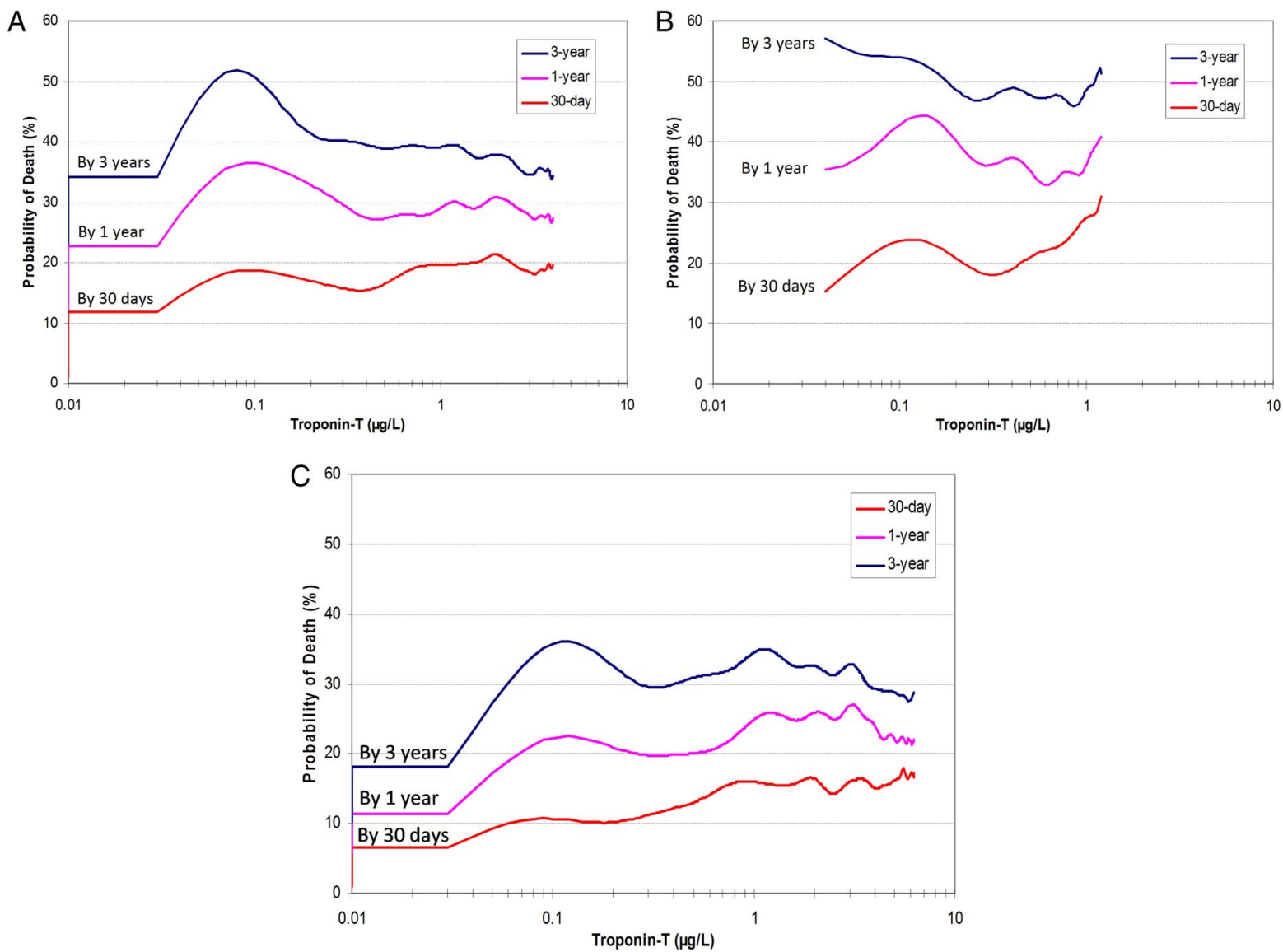

Figure 5 Probability of death within 30 days, 1 year and 3 years according to the TnT level in 2005. For all three figures, the $Y$ axis is the probability of death. The $\mathrm{X}$ axis is TnT drawn on a log-10 scale. ACS, acute coronary syndromes; TnT, troponin T. 


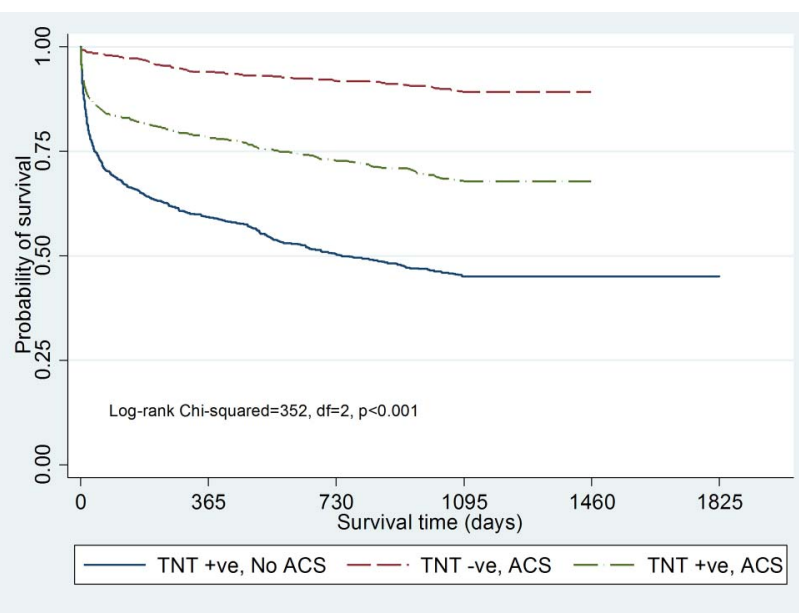

Figure 6 Survival curves are plotted by the Kaplan-Meier method, showing 3-year mortality according to the TnT level in 2005 in patients with TnT test (TnT-positive-No ACS $(n=823)$, TnT-positive-ACS $(n=840)$ and TnT negative-ACS $(n=707))$. ACS, acute coronary syndromes; $\mathrm{TnT}$, troponin $\mathrm{T}$.

cardiology wards and coronary interventions are likely to miss many patients admitted with ACS to services other than cardiology, especially in high-risk groups such as older people or those with other important medical comorbidities.

Our data from 2005 suggest an annual incidence of MI of 1.56 per thousand population; of ACS of 2.86 per thousand and of ACS or positive TnT of 4.33 per thousand. In our region, using MI identified by hospital discharge statistics alone, the incidence of MI had dropped by $40 \%$ from 1.66 per thousand per year in 1998 to 0.97 in 2005. This compares to 64436 admissions in England for acute MI using hospital episode statistics, which gives a rate of 1.29 per thousand in $2005 .{ }^{10}$ Of these, 49017 patients were reported as having STEMI ${ }^{11}$ and 13489 with non-STEMI, ${ }^{12}$ which suggests substantial underreporting of non-STEMI. However, many previous reports have quoted incidence rates excluding younger people from the denominator. ${ }^{1}$ If only those people aged $>35$ years are considered, our local incidence of MI is closer to 3 per thousand. These data are also likely to be an underestimate of the rate of MI in the community, as up to $30 \%$ of people with an MI may die before they reach hospital, ${ }^{13} 14$ and up to $40 \%$ of patients who survive an MI do not have symptoms that trigger urgent referral to the hospital. ${ }^{15-18}$

About half of the patients with a positive TnT were not identified as having ACS by any of the survey methods. There are reasons other than ACS for elevation in TnT, including strenuous exercise, heart failure, trauma, renal failure, sepsis, gastrointestinal bleeding, pulmonary embolism and myocarditis. ${ }^{19-24}$ Others have also reported a higher mortality rate in patients without coronary disease but with elevated serum troponin. ${ }^{25}$ It is likely that the clinical diagnosis of ACS was missed in some cases and uncertain in others. Some of these patients may have has, so called, type-2 MI reflecting myocardial energy demand/supply imbalance rather than an acute vascular occlusion. ${ }^{26-28}$ For instance, in patients with heart failure, TnT is often elevated, especially (although not exclusively) during acute exacerbations. $^{29}$ Postmortem data suggest that there is a substantial rate of MI in this population that is not associated with classical symptoms. ${ }^{30} 31$ The high mortality rate among patients with elevated TnT who were not identified as having ACS may well indicate heart and/or renal failure. Newer, high-sensitivity assays for troponin will increase the diagnostic sensitivity for ACS but at the potential cost of a substantial decline in specificity and

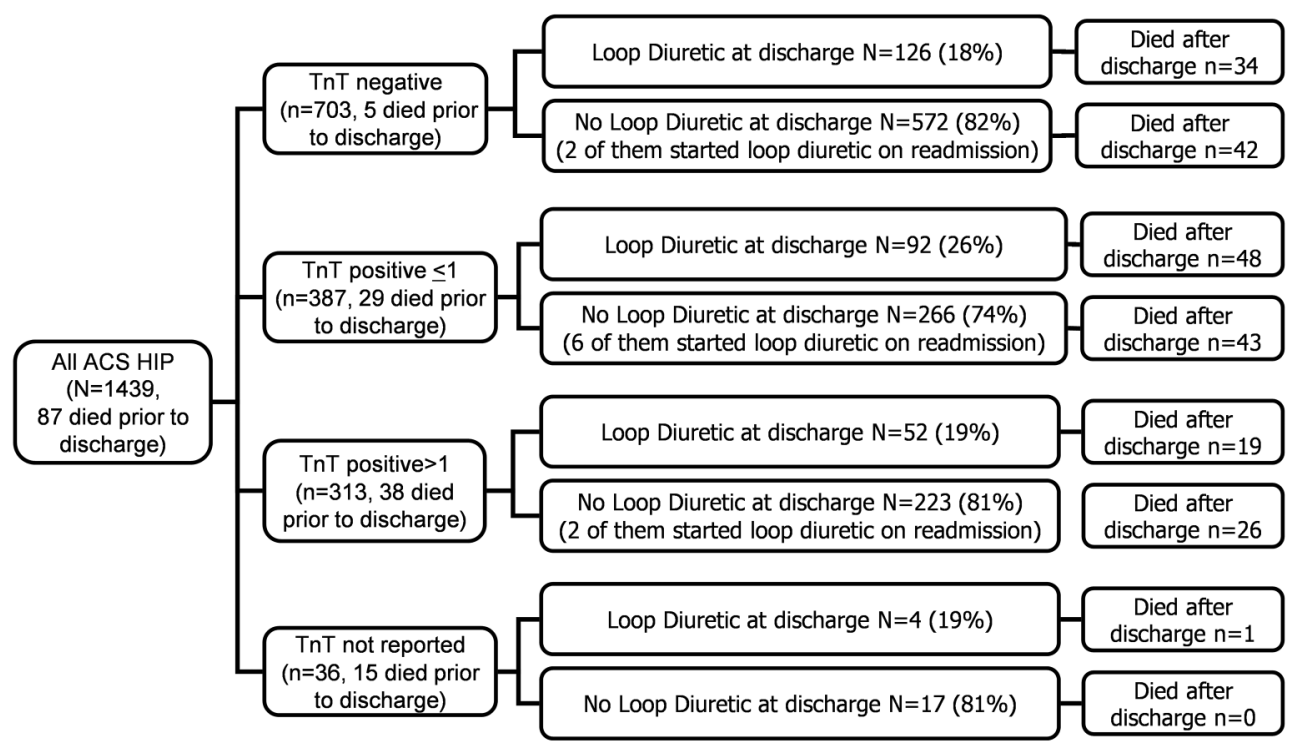

Figure 7 Use of loop diuretics as a general indicator of adverse outcome. ACS, acute coronary syndromes; HIP, Hull Infarction Project; TnT, troponin T. 
an increase in diagnostic confusion. ${ }^{32} 33$ Indeed, these new assays may have greater clinical utility in the heart failure outpatient clinic than in the emergency room. $^{33} 34$

In contrast to a previous report, ${ }^{35}$ on far fewer patients, we found that 3-month mortality was similarly high in patients with a raised troponin on a 'firstgeneration' assay whether the elevation was modest or substantial. Our hospital policy, in 2005, was to measure TnT once at least 12 hours after the onset of symptoms. Single measurements may be a poor guide to the extent of myocardial damage. Alternatively, even modest increases in TnT may indicate the presence of unstable plaque and the threat of further events that provoke arrhythmias or cause substantial cardiac damage.

The outcome from MI in our unselected population remains very different from that reported among patients in randomised controlled trials of ACS. The exclusion of high-risk, elderly patients with multiple comorbidities from trials probably accounts for most of the disparity. However, failure to refer patients for cardiology advice and to undertake timely intervention may also contribute to poor outcomes. Nevertheless, in-patient mortality for MI in our hospital dropped from $22 \%$ in 1998 , a mortality that was consistent with that predicted by the international GRACE score, ${ }^{36}$ to $11 \%$ in 2005; some of this difference might be accounted for by differences in survey method. Since this survey, a regional primary angioplasty service has been implemented that may have improved outcomes further. As noted in the present and previous studies, ${ }^{37}$ it is patients who develop clinical evidence of heart failure who fare particularly badly. Heart failure precedes the majority of deaths after MI. ${ }^{38}$ Patients with substantial symptoms or signs of congestion require treatment with loop diuretics and, therefore, their prescription can be considered a sensitive marker of the development of heart failure. However, prescription of loop diuretics may lack specificity for a diagnosis of heart failure; cardiac imaging and biomarkers should be used to confirm the diagnosis.

\section{CONCLUSION}

The incidences of ACS and MI are highly dependent on the method of case ascertainment. Failure to identify older, high-risk patients leads to overoptimistic estimations about the prognosis of ACS, underestimation of the resources needed to manage it and misleading perceptions about the adequacy of care that might lead to complacency. An increase in TnT and the use of diuretics are simple clinical markers of an adverse prognosis. Even a slight elevation in TnT is associated with a poor outcome whether or not a patient is diagnosed with ACS. Mortality was higher among patients with a positive TnT who did not have a documented diagnosis of ACS, which may partly reflect the age and underlying disease in this patient group, but could also reflect suboptimal management of cardiovascular risk.
Acknowledgements The authors thank the MINAP coordinator (Neil Richardson), the hospital information department (John Taylor) and the chemical pathology laboratory staff (Lisa Dawson). The authors also wish to acknowledge the contribution of Janet Bristow who sadly died before the study was complete. This paper is a part of my thesis.

Contributors JGFC contributed to study design and wrote the manuscript. NS is responsible for making tables and data collection. PA involved in data collection. HP and KG contributed to statistics and tables. EK is responsible for providing some of the data. ST, AH, FA and ALC are responsible for finding patients and collecting data. AR is responsible for statistics and figures.

Funding This research was supported by an unrestricted grant from Pfizer. JGFC reports speaker's honoraria and research support from Roche Diagnostics.

Competing interests None declared.

Ethics approval Research and development Department of Hull and East Yorkshire.

Provenance and peer review Not commissioned; externally peer reviewed.

Data sharing statement No additional data are available.

Open Access This is an Open Access article distributed in accordance with the Creative Commons Attribution Non Commercial (CC BY-NC 4.0) license, which permits others to distribute, remix, adapt, build upon this work noncommercially, and license their derivative works on different terms, provided the original work is properly cited and the use is non-commercial. See: http:// creativecommons.org/licenses/by-nc/4.0/

\section{REFERENCES}

1. Cleland JG, Torabi A, Khan NK. Epidemiology and management of heart failure and left ventricular systolic dysfunction in the aftermath of a myocardial infarction. Heart 2005;91(Suppl 2):ii7-13.

2. MINAP Hospital Reports. Myocardial ischaemia national audit project (MINAP). MINAP Hospital Reports, 2008. The Cardiac Network of Wales

3. Herrett E, Smeeth L, Walker L, et al., MINAP Academic Group. The Myocardial Ischaeimia National Audit Project (MINAP). Heart 2010;96:1264-7.

4. Torabi A, Cleland JG, Khan NK, et al. The timing of development and subsequent clinical course of heart failure after a myocardial infarction. Eur Heart $J$ 2008;29:859-70.

5. Quinn T, Weston C, Birkhead J, et al. Redefining the coronary care unit: an observational study of patients admitted to hospital in England and Wales in 2003. QJM 2005;98:797-802.

6. Birkhead JS, Weston C, Lowe D. Impact of specialty of admitting physician and type of hospital on care and outcome for myocardial infarction in England and Wales during 2004-5: observational study. BMJ 2006;332:1306-11.

7. Birkhead JS, Walker L, Pearson M, et al. Improving care for patients with acute coronary syndromes: initial results from the National Audit of Myocardial Infarction Project (MINAP). Heart 2004;90:1004-9.

8. World Health Organization. International Statistical Classification of Diseases and Related Health Problems 10th Revision, Version for 2005. website 2014. http://apps.who.int/classifications/apps/icd/ icd10online2005/fr-icd.htm

9. Herrett E, Shah AD, Boggon R, et al. Completeness and diagnostic validity of recording acute myocardial infarction events in primary care, hospital care, disease registry, and national mortality records: cohort study. BMJ 2013;346:f2350.

10. Hospital Episode Statistics: Primary diagnosis: summary, 2005-06. 8 A.D. p. 1-213.

11. Horne S, Weston C, Quinn T, et al. The impact of pre-hospital thrombolytic treatment on re-infarction rates: analysis of the Myocardial Infarction National Audit Project (MINAP). Heart 2009;95:559-63.

12. Birkhead JS, Weston CF, Chen R. Determinants and outcomes of coronary angiography after non-ST-segment elevation myocardial infarction. A cohort study of the Myocardial Ischaemia National Audit Project (MINAP). Heart 2009;95:1593-9.

13. Volmink JA, Newton JN, Hicks NR, et al. Coronary event and case fatality rates in an English population: results of the Oxford myocardial infarction incidence study. The Oxford Myocardial Infarction Incidence Study Group. Heart 1998;80:40-4. 
14. Rosamond WD, Chambless LE, Folsom AR, et al. Trends in the incidence of myocardial infarction and in mortality due to coronary heart disease, 1987 to 1994. N Engl J Med 1998;339:861-7.

15. Dorsch MF, Lawrance RA, Sapsford RJ, et al. Poor prognosis of patients presenting with symptomatic myocardial infarction but without chest pain. Heart 2001;86:494-8.

16. Kannel WB, Abbott RD. Incidence and prognosis of unrecognized myocardial infarction. An update on the Framingham study. $N$ Engl $J$ Med 1984;311:1144-7.

17. Brieger D, Eagle KA, Goodman SG, et al. Acute coronary syndromes without chest pain, an underdiagnosed and undertreated high-risk group: insights from the Global Registry of Acute Coronary Events. Chest 2004;126:461-9.

18. Hansson L, Zanchetti A, Carruthers SG, et al. Effects of intensive blood-pressure lowering and low-dose aspirin in patients with hypertension: principal results of the Hypertension Optimal Treatment (HOT) randomised trial. HOT Study Group. Lancet 1998;351:1755-62.

19. Mockel M, Schindler R, Knorr L, et al. Prognostic value of cardiac troponin $\mathrm{T}$ and I elevations in renal disease patients without acute coronary syndromes: a 9-month outcome analysis. Nephrol Dial Transplant 1999;14:1489-95.

20. Krahn J, Parry DM, Leroux M, et al. High percentage of false positive cardiac troponin I results in patients with rheumatoid factor. Clin Biochem 1999;32:477-80.

21. Vasile VC, Babuin L, Rio Perez JA, et al. Long-term prognostic significance of elevated cardiac troponin levels in critically ill patients with acute gastrointestinal bleeding. Crit Care Med 2009;37: $140-7$.

22. Thygesen K, Mair J, Giannitsis E, et al. Study Group on Biomarkers in Cardiology of ESC Working Group on Acute Cardiac Care. How to use high-sensitivity cardiac troponins in acute cardiac care. Eur Heart J 2012;33:2252-7.

23. Vasile VC, Chai HS, Abdeldayem D, et al. Elevated cardiac troponin T levels in critically ill patients with sepsis. Am J Med 2013;126:1114-21.

24. Baron JM, Lewandrowski EL, Januzzi JL, et al. Measurement of high-sensitivity troponin $\mathrm{T}$ in noncardiac medical intensive care unit patients. Correlation to mortality and length of stay. Am J Clin Pathol 2014:141:488-93

25. Chew DP, Briffa TG, Alhammad NJ, et al. High sensitivity-troponin elevation secondary to non-coronary diagnoses and death and recurrent myocardial infarction: an examination against criteria of causality. Eur Heart J Acute Cardiovasc Care 2015;4:419-28.

26. Alpert JS, Thygesen KA, White HD, et al. Diagnostic and therapeutic implications of type 2 myocardial infarction: review and commentary. Am J Med 2014:127:105-8.

27. Saaby L, Poulsen TS, Diederichsen AC, et al. Mortality rate in type 2 myocardial infarction: observations from an unselected hospital cohort. Am J Med 2014;127:295-302.

28. Sandoval Y, Smith SW, Thordsen SE, et al. Supply/demand type 2 myocardial infarction: should we be paying more attention? J Am Coll Cardiol 2014;63:2079-87.

29. Omland T, de Lemos JA, Sabatine MS, et al. A sensitive cardiac troponin T assay in stable coronary artery disease. $N$ Engl $J$ Med 2009;361:2538-47.

30. Uretsky BF, Thygesen K, Armstrong PW, et al. Acute coronary findings at autopsy in heart failure patients with sudden death: results from the assessment of treatment with lisinopril and survival (ATLAS) trial. Circulation 2000;102:611-16.

31. Orn S, Cleland JG, Romo M, et al. Recurrent infarction causes the most deaths following myocardial infarction with left ventricular dysfunction. Am J Med 2005;118:752-8.

32. Mills NL, Lee KK, McAllister DA, et al. Implications of lowering threshold of plasma troponin concentration in diagnosis of myocardial infarction: cohort study. BMJ 2012;344:e1533.

33. de Lemos JA. Increasingly sensitive assays for cardiac troponins: a review. JAMA 2013;309:2262-9.

34. Lok DJ, Klip IT, Lok SI, et al. Incremental prognostic power of novel biomarkers (growth-differentiation factor-15, high-sensitivity C-reactive protein, galectin-3, and high-sensitivity troponin-T) in patients with advanced chronic heart failure. Am J Cardiol 2013;112:831-7.

35. Ohman EM, Armstrong PW, Christenson RH, et al. Cardiac troponin $T$ levels for risk stratification in acute myocardial ischemia. GUSTO IIA Investigators. N Engl J Med 1996;335:1333-41.

36. Granger CB, Goldberg RJ, Dabbous O, et al. Predictors of hospital mortality in the global registry of acute coronary events. Arch Intern Med 2003;163:2345-53.

37. Ezekowitz JA, Kaul P, Bakal JA, et al. Declining in-hospital mortality and increasing heart failure incidence in elderly patients with first myocardial infarction. J Am Coll Cardiol 2009;53:13-20.

38. Torabi A, Rigby AS, Cleland JG. Declining in-hospital mortality and increasing heart failure incidence in elderly patients with first myocardial infarction. J Am Coll Cardiol 2009;55:79-81. 